2 Karpel J T, Peden V H. Copper deficiency in long-term parenteral nutrition. J Pediatr 1972; 80: 32-6.

3 Ashkenazi A, Levin S, Djaldetti M, Fishel E, Benvinisti D. The syndrome of neonatal copper deficiency. Pediatrics $1973 ; 52$ : 525-33.

4 Al-Rashid R A, Spangler J. Neonatal copper deficiency. N Engl J Med 1971; 285: 841-3.

5 Sturgeon P, Brubaker C. Copper deficiency in infants. A syndrome characterised by hypocupremia, iron deficiency anemia, and hypoproteinemia. Am J Dis Child 1956; 92: 254-65.

6 Griscom N T, Craig J N, Neuhauser E B D. Systemic bone disease developing in small premature infants. Pediatrics 1971 ; 48: 883-95.

7 Wilson J F, Lahey M E. Failure to induce dietary deficiency of copper in premature infants. Pediatrics $1960 ; 25$ : 40-9.

8 Lee C W G, Yu J S, Turner B B, Murray K E. Trimethylaminuria: fishy odors in children. $N$ Engl J Med 1976; 295: 937-8.

Correspondence to Dr I Blumenthal, Leeds General Infirmary, Department of Paediatrics, Great George Street, Leeds LS1 3EX.

\title{
Late cerebral relapse of congenital toxoplasmosis
}

\author{
RICHARD O ROBINSON AND ROBERT J BAUMANN \\ Department of Neurology, University of Kentucky Medical Center, Lexington
}

SUMMARY Focal encephalitis occurred in a girl with activation of chorioretinitis which on clinical and serological grounds was taken to be caused by toxoplasma. The encephalitis and acute ocular inflammation resolved with treatment with pyrimethamine and sulphadiazine. This is presumably an example of reactivation of congenital cerebral toxoplasmosis.

Congenital ocular toxoplasmosis may be exacerbated years after the initial infection. ${ }^{1}$ It has been suggested that similar exacerbations of neurological toxoplasmosis occur, ${ }^{2-3}$ but these have been difficult to demonstrate. We describe an 8-year-old girl who had focal encephalitis associated with reactivation of ocular toxoplasmosis. We suggest this represents an example of reactivation of congenital central nervous system toxoplasmosis.

\section{Case report}

The patient had been born at term in eastern Kentucky after a pregnancy unmarred by maternal fever or lymphadenopathy. At 6 months strabismus had been noted, and at 3 years an optometrist diagnosed bilateral chorioretinitis. This was confirmed 2 years later by an ophthalmologist who found her bilateral visual acuity to be 20/40.

By the time she was aged 9, her school performance had deteriorated and her bilateral visual acuity was found to be 20/200. The left eye showed yellowish macular exudates with pigmentary irregularity and intraretinal oedema. A slight haze marred the overlying vitreous. Several small inactive scars lined the peripheral retina. The right eye had one large macular scar and several smaller peripheral ones, all appearing inactive. The optic discs seemed normal. The toxoplasma immunofluorescent antibody (IFA) titre was 1:64. Treatment with pyrimethamine and corticosteroids was offered but refused. She began to experience increasingly frequent headaches. Two months later she had five closely-spaced grand mal seizures. The first few were predominantly left-sided before becoming generalised. Immediately after the seizures she was afebrile, orientated, and co-operative. Her neck was supple and there were no focal neurological signs. The eye findings were similar to those described above. CSF obtained at lumbar puncture was under normal pressure but contained 100 nucleated cells (all lymphocytes) $/ \mathrm{mm}^{3}$, with a glucose concentration of $50 \mathrm{mg} / 100 \mathrm{ml}(2 \cdot 8 \mathrm{mmol} / \mathrm{l})$, protein concentration $19 \mathrm{mg} / 100 \mathrm{ml}$, and IgG concentration of $2.8 \mathrm{mg} / 100 \mathrm{ml}$. Bacterial and fungal cultures were sterile and cryptococcal antigen was absent. Her serum toxoplasma IFA titre was 1:256. An EEG 18 hours after the last seizure showed right posterior temporal 0.5 to $1 \mathrm{~Hz}$ slow wave activity, which persisted in a second EEG 4 days later. Skull and chest $x$-rays, and CAT of the head were normal. Serum VDRL and FTA were nonreactive, serum rubella titre was less than $1: 10$, serum herpes titre was less than 1:8, and cytomegalovirus titre was positive only to $1: 8$ dilution. The girl's mother had a serum toxoplasma IFA titre of $1: 256$.

The child was treated with folinic acid, sulpha- 
diazine, and pyrimethamine for $\mathbf{3 0}$ days and placed on phenytoin.

During treatment her chorioretinitis became quiescent, and she had no further seizures. CSF obtained 2 months later contained 2 nucleated cells $/ \mathrm{mm}^{3}$, a protein concentration of $18 \mathrm{mg} / 100 \mathrm{ml}$, and a glucose concentration of $55 \mathrm{mg} / 100 \mathrm{ml}(3 \cdot 1$ $\mathrm{mmol} / \mathrm{l})$. It did not contain toxoplasma antibodies although her serum toxoplasma IFA titre remained at 1:256. An EEG done 3 months after the end of treatment was normal. Her visual acuity had improved to 20/50 (left) and 20/70 (right). The left macula showed a quiescent scar with early pigmentation in place of the previously observed oedema and exudates.

\section{Discussion}

Exacerbations of ocular toxoplasmosis have been well described, occurring in 20 of 300 congenitally infected infants up to 20 years after birth. ${ }^{1}$ The diagnosis in this girl was based on early strabismus, typical funduscopic appearance, antitoxoplasmic activity in blood, and failure to demonstrate any other known cause of chorioretinitis. Although the prevalence of acquired toxoplasmosis in eastern Kentucky is unknown, only $5 \%$ of children aged between 5 and 9 living in nearby Cincinnati had positive toxoplasma skin tests. ${ }^{4}$ Chorioretinitis, a common sequel to congenital infection, is rarely the result of postnatal disease. Declining visual acuity, vitreous haziness, and intraretinal oedema indicate exacerbation of the congenital ocular infection.

A similar course of events affecting the central nervous system was reported for only 2 children. ${ }^{15}$ One (aged 9 years) presented with acute internal hydrocephalus caused by aqueductal stenosis, and the other (aged 8 years) with a seizure. Although in one child high CSF antitoxoplasmic activity was demonstrated, ${ }^{5}$ in neither case was any other CSF finding reported. Evidence that the acute events were caused by inflammation is therefore lacking and other factors may have been responsible. In our case, the transient appearance of inflammatory cells in the CSF in conjunction with symptoms and EEG evidence of focal cerebral dysfunction after a flare up of congenital ocular toxoplasmosis suggests reactivation of central nervous system toxoplasmosis. This presumably took the form of recrudescence of a meningeal nidus, the subjacent inflammatory reaction inducing an epileptic focus. Berengo and Frezzotti ${ }^{3}$ reported the unique experience of finding toxoplasma-like organisms in CSF in 13 of 19 patients with acute ocular toxoplasmosis. Three of their cases clearly had exacerbations of congenital disease.
If their findings are confirmed, patients with ocular toxoplasmosis may continue to harbour viable toxoplasma elsewhere in the CNS more commonly than hitherto supposed.

Recrudescence presumably occurs by rupture of the pseudocysts. Concomitant exacerbations of ocular and cerebral toxoplasmosis could occur by a variety of mechanisms. Chronic infection may depend on a delicate immunological balance between the quiescent parasite and the host. As far as CNS toxoplasmosis is concerned, cellular immunity appears to be more important than circulating antibody in maintaining this balance..$^{6-7}$ Temporary depression in cellular immunity caused, for example, by an intercurrent viral infection could allow recrudescence wherever pseudocysts contain viable organisms. The apparent rarity of CNS recrudescence may be explained by comparative stability of pseudocysts, the relative inaccessability of the brain to circulating antibody, or simply by failure to perform spinal punctures on patients with ocular exacerbations.

Administration of sulphadiazine and pyrimeamine was associated with apparent resolution of our patient's retinal and cerebral inflammation. However, it should be noted that these drugs do not kill the organisms and she may therefore be at risk from further exacerbations.

This child's care was in part funded by a grant from the Growth and Development Branch of the Kentucky Bureau of Health Services, Division for Maternal and Child Health Services.

\section{References}

1 Desmonts G, Couvreur J. Congenital toxoplasmosis. N Engl J Med 1974; 290: 1110-16.

2 Crothers B. Toxoplasmic encephalitis; clinical experience. J Nerv Ment Dis 1943; 97: 86-92.

8 Berengo A, Frezzotti R. Active neuro-ophthalmic toxoplasmosis. Bibl Ophthalmol 1962; 59: 265-343.

4 Feldman H A, Sabin A B. Skin reactions to toxoplasmic antigen in people of different ages without known history of infection. Pediatrics $1949 ;$ 4: 798-804.

5 Piussan C, Desmonts G, Mozziconacci P. Évoluvité neurologique tardive d'une toxoplasmose congénitale demontré par l'étude du LCR. Ann Pediatrie 1971; 18: 224-7.

- Frenkel J K. Toxoplasmosis. Curr Top Pathol 1971; 54: 28-75.

7 Frenkel J K, Nelson B M, Arias-Stella J. Immunosuppression and toxoplasmic encephalitis. Hum Pathol 1975; 6: 97-111.

Correspondence to $\mathrm{Dr} R$ O Robinson, Department of Neurology, University of Kentucky, Lexington, Kentucky 40506, USA. 